E3S Web of Conferences 1, 07003 (2013)

DOI: $10.1051 / \mathrm{e} 3$ sconf/20130107003

(c) Owned by the authors, published by EDP Sciences, 2013

\title{
Explaining trends in tropospheric mercury using global modeling
}

\author{
N. E. Selin ${ }^{1}$ and S. Song ${ }^{2}$ \\ ${ }^{1}$ Engineering Systems Division and Department of Earth, Atmospheric and Planetary Sciences, Massachusetts Institute \\ of Technology, Cambridge, MA, USA, selin@mit.edu \\ ${ }^{2}$ Department of Earth, Atmospheric and Planetary Sciences, Massachusetts Institute of Technology, Cambridge, MA, \\ USA, song33@mit.edu
}

\begin{abstract}
Multiple observational analyses have identified a decreasing trend over the past decade in surface concentrations of gaseous elemental mercury (GEM), from sites in both the Northern and Southern hemisphere. We use two model-based approaches to identify sets of parameters that could quantitatively explain observed trends in mercury. Using a 12-box model, we quantify which combinations of factors including changes in anthropogenic emissions, oceanic and land evasion, and atmospheric oxidation rates that can explain observed tropospheric mercury decreases. We then use the GEOS-Chem chemical transport model to further examine source attribution at measurement sites where decreasing trends have been observed. We combine these analyses to generate quantitative hypotheses to explain observed trends. We suggest that the tropospheric decline may be best explained by multiple, reinforcing factors.
\end{abstract}

Key words: tropospheric mercury, global mercury cycle, box model, global model, trends, sensitivity

\section{Introduction}

Environmental impacts and human health risks of mercury $(\mathrm{Hg})$ have drawn a wide range of concern from the public and decision-makers (Selin, 2011). $\mathrm{Hg}$ is released into the atmosphere mainly as three forms, i.e., gaseous elementary mercury $(\mathrm{GEM}, \mathrm{Hg}(0))$, reactive gaseous mercury (RGM, $\mathrm{Hg}(\mathrm{II})$ in gas phase), and particle-bound mercury (PBM, $\mathrm{Hg}(\mathrm{II})$ in particle phase). More than $90 \%$ of the total mercury in the troposphere is in the form of GEM (Lindberg et al., 2007). In the present-day global cycle, anthropogenic emission, natural emission, and the re-emission from the legacy of previously deposited mercury each contributes about $1 / 3$ to the total mercury inventory (Pirrone et al., 2010). Global anthropogenic emission was believed to be a rough constant in the last 20 years given decreasing trends in developed regions (e.g., North America, Europe) and rapidly increasing trends in industrializing areas (e.g., East Asia) (Streets et al., 2009). As a result, atmospheric mercury concentration is considered to basically remain unchanged in recent years. However, Slemr et al. (2011) reported that the tropospheric mercury concentration had experienced a decrease of about $20 \sim 38 \%$ between 1996 and 2009 based on long term background data in both Northern Hemisphere (Mace Head, Ireland) and Southern Hemisphere (Cape Point, South Africa). Similar decreasing trends of GEM were also observed in the background sites of North America (Alert, Canada; Thompson Farm, USA) (Cole and Steffen, 2010; Mao and Talbot, 2011). These trends indicated a considerable change in the global biogeochemical cycle of mercury. Several possible explanations have been suggested, including: (1) the decrease of anthropogenic emission, (2) the acceleration of the oxidizing capacity in the atmosphere, (3) the decrease of emissions from the legacy of historical mercury use (e.g., Hg-containing products such as batteries, thermometers and switches) and emissions, (4) changing emissions from the oceans and the lands, and (5) others possible factors such as climate change (Slemr et al., 2011; Streets et al., 2011).

In this study, we use a global multi-compartmental box model and the global mercury simulation in the GEOS-Chem global chemical transport model to assess required changes of emissions or process rates corresponding to a $20 \%$ decrease in tropospheric mercury, both globally and at measurement locations.

\section{Methods}

We use two models in this study: a 12-compartment global box model, and the GEOS-Chem chemical transport model.

We construct a twelve-compartmental global box-model that is based on our up-to-date estimates of global mercury budgets (Selin et al., 2008). As illustrated 
in Figure 1, this model includes three fast-cycling surface reservoirs (the troposphere, the fast land, and the surface ocean), three slow-cycling reserviors (the slow land, the deep ocean, and the final sediment pool), and the stratosphere. The troposphere, the ocean and the land are divided hemispherically in order that the different responses of mercury mass in both hemispheres can be evaluated. Inter-hemispheric exchanges of mercury only occur in the atmosphere. To simplify the model, we do not consider the partitioning of $\mathrm{Hg}$ (II) between the gas and particle phase. It is assumed that all the biogeochemistry processes are in the first order and the constant rates remain the same in the preindustrial and present-day periods.

We first run the model to steady state using a geogenic emission of $500 \mathrm{Mg} / \mathrm{a}$, including $365 \mathrm{Mg} / \mathrm{a}$ in the Northern Hemisphere and $135 \mathrm{Mg} / \mathrm{a}$ in the Southern Hemisphere. We then conduct a time-dependent simulation for 100 a to represent the disturbed global mercury cycle in the industrial period. Total anthropogenic emission is assumed as Eq. 1: Anthro_Emis $=3000 *(\mathrm{t} / 100)^{2}$

The ratio of anthropogenic emission between $\mathrm{NH}$ and $\mathrm{SH}$ is assumed as $5: 1$. After these spin-up processes, the resulting mass of GEM in the troposphere is about 4000 $\mathrm{Mg}$, with an inter-hemispheric ratio of 1.46 ( $\mathrm{NH}$ to $\mathrm{SH}$ ).

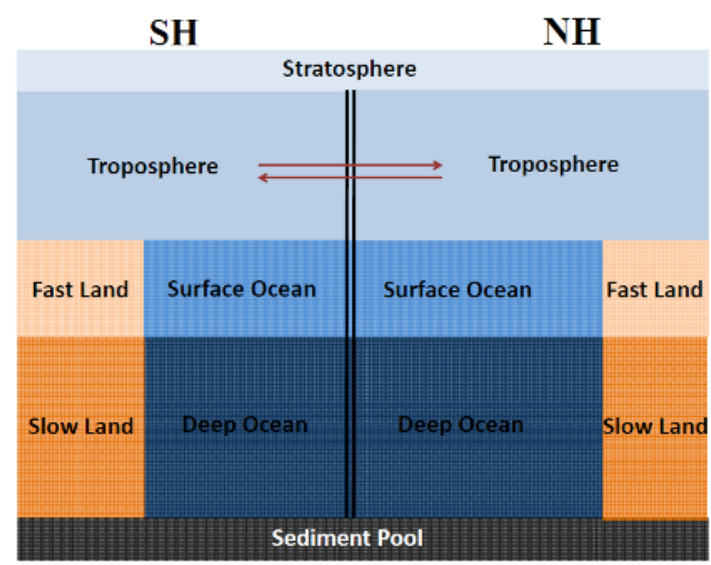

Fig. 1. Schematic diagram of the global mercury multi-compartmental box model.

To further assess spatial variation in tropospheric GEM, we use the GEOS-Chem v9-01-02, with mercury chemistry as specified by Holmes et al. (2010). GEOS-Chem is driven by meteorological observations from the NASA Goddard Earth Observing System (GEOS-5). GEOS-5, and we run simulations here at $4^{\circ} \times 5^{\circ}$ latitude-longitude resolution horizontally and 47 vertical levels. The GEOS-Chem global mercury simulation is a coupled land-ocean-atmosphere simulation and includes three mercury species: $\operatorname{Hg}(0)$, $\mathrm{Hg}(\mathrm{II})$, and $\mathrm{Hg}(\mathrm{P})$. The $\mathrm{Hg}$ model has been extensively evaluated against a global suite of observations, including interhemispheric gradient and seasonal variation of $\operatorname{Hg}(0)$, day-to-day variations at selected sites for $\mathrm{Hg}(0), \operatorname{Hg}(\mathrm{II})$ and $\mathrm{Hg}(\mathrm{P})$, and wet deposition measurements over the U.S. and Europe (Selin et al. 2008; Holmes et al., 2010). To identify source attribution at measurement sites, we conduct sensitivity simulations with GEOS-Chem by running the model with direct anthropogenic, land, ocean, and biomass burning sources turned off, and diagnose the contribution of these sources by difference.

\section{Results and Discussion}

Three factors were selected in the box model to conduct sensitivity analysis: anthropogenic emission (standard value: $3000 \mathrm{Mg} / \mathrm{a}$ ), evasion from the ocean (standard value: $0.42 \mathrm{a}^{-1}$ ), and the oxidizing capacity in the atmosphere (standard value: $3 \mathrm{a}^{-1}$ ). We tested response to instantaneous changes in these values, and continued to run the model for 15 a. A control simulation was also conducted assuming that no factors had changed.

Figure 2 shows the ratios of the tropospheric GEM mass in both Hemispheres relative to that in control simulation. Changes in individual source terms alone require large changes to explain observed decreases on the order of $20 \%$. For example, as shown in Figure 2, explaining a decrease in tropospheric GEM in both the Northern and Southern hemispheres through anthropogenic emission changes alone requires a decline of c. $1000 \mathrm{Mg} \mathrm{a}^{-1}$, inconsistent with present estimates of anthropogenic emission in this period. A change in evasion rate from the ocean alone would require a factor of 2-3 change to cause a $20 \%$ decrease in tropospheric GEM mass. Allowing more than one factor to change simultaneously requires less change in any one factor.

Using GEOS-Chem, we identify source contributions to surface concentrations of GEM at measurement sites where trends have been identified. Figure 4 shows the percentage source contributions to surface GEM at Mace Head (panel (a)) and Cape Point (panel (b)). We find that ocean sources contribute substantially more to GEM surface concentrations at Cape Point than at Mace Head. This analysis supports the idea of multiple causation for global tropospheric GEM trends.

\section{Conclusion}

From our box model analysis, we hypothesize that trends in tropospheric GEM as observed in both the southern and northern hemisphere may be a result of multiple reinforcing factors rather than a single process or emission change. We identified a feasible set of parameter changes through our multi-criteria analysis. From our GEOS-Chem model analysis, we further showed that change in contributions from a single source are unlikely to explain simultaneous decreases at different measurement sites.

\section{Acknowledgements}

The authors acknowledge support from the U.S. National Science Foundation, Atmospheric Chemistry Program, under grant \#1053648. 

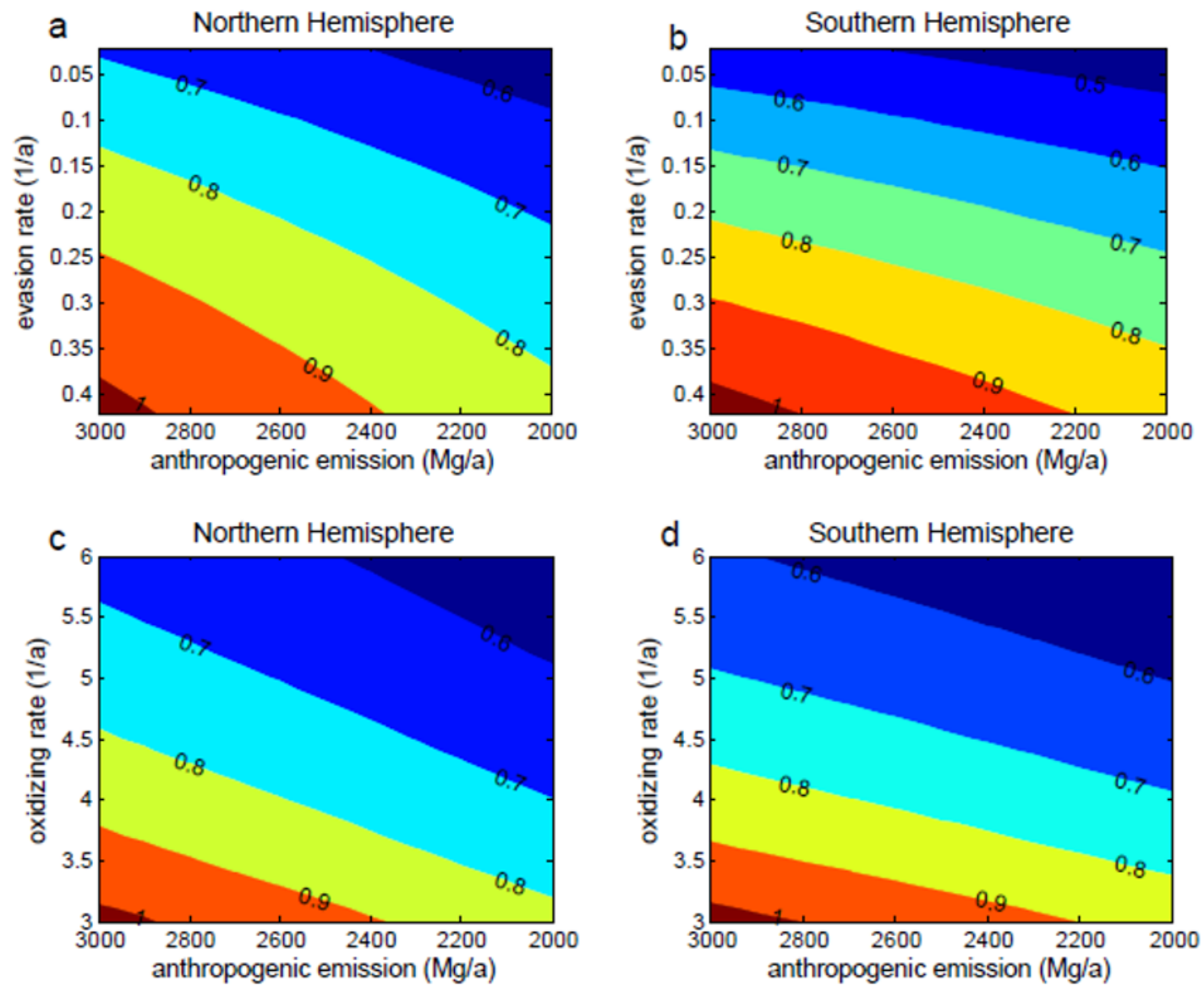

Fig. 2. Ratios of the tropospheric GEM mass relative to control simulation given the changes in anthropogenic emission, evasion from the ocean, and oxidizing capacity in the atmosphere
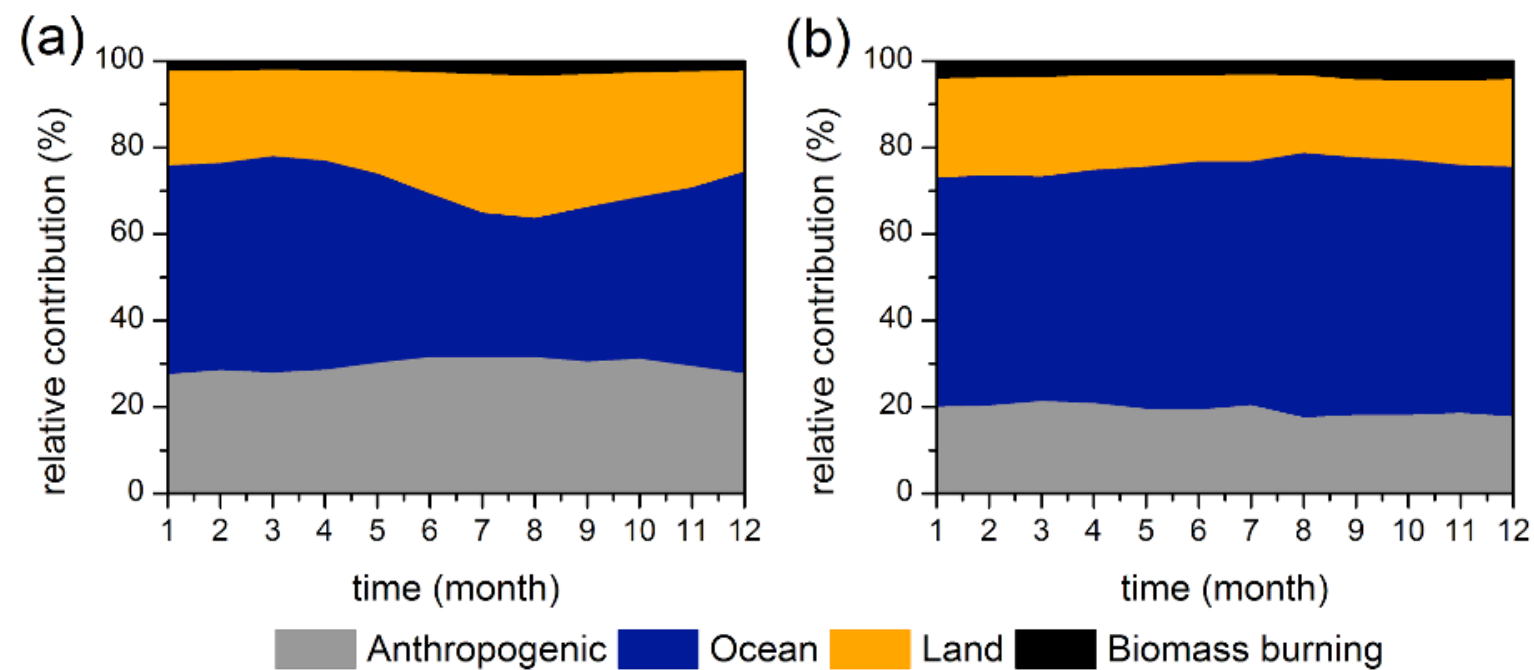

Fig. 3. Percentage source contributions to surface GEM at a) Mace Head and b) Cape Point stations using the GEOS-Chem model. 


\section{References}

Cole AS, Steffen A. Trends in long-term gaseous mercury observations in the Arctic and effects of temperature and other atmospheric conditions. Atmos Chem Phys 2010; 10: 4661-4672.

Holmes, CD, Jacob DJ, Corbitt ES, Mao J, Yang X, Talbot R, and Slemr F Global atmospheric model for mercury including oxidation by bromine atoms. Atmos. Chem. Phys. 2010; 10:12037-12057.

Lindberg S, Bullock R, Ebinghaus R, Engstrom D, Feng XB, Fitzgerald W, Pirrone N, Prestbo E, Seigneur C. A synthesis of progress and uncertainties in attributing the sources of mercury in deposition. Ambio 2007; 36: 19-32.

Mao H, Talbot R. Speciated mercury at marine, coastal, and inland sites in New England - part 1: temporal variability. Atmos Chem Phys 2011; 11:32301-32336.

Pirrone N, Cinnirella S, Feng X, Finkelman RB, Friedli
HR, Leaner J, Mason R, Mukherjee AB, Stracher GB, Streets DG, Telmer K. Global mercury emissions to the atmosphere from anthropogenic and natural sources. Atmos Chem Phys 2010; 10:5951-5964.

Selin NE. Science and strategies to reduce mercury risks: a critical review. J Environ Monitor 2011; 13:2389-2399.

Selin NE, Jacob DJ, Yantosca RM, Strode S, Jaegle L, Sunderland EM. Global 3-D land-ocean-atmosphere model for mercury: Present-day versus preindustrial cycles and anthropogenic enrichment factors for deposition. Global Biogeochem Cy 2008; 22.

Streets DG, Zhang Q, Wu Y. Projections of global mercury emissions in 2050. Environ Sci Technol 2009; 43:2983-2988.

Streets DG, Devane MK, Lu Z, Bond TC, Sunderland EM, Jacob DJ. All-Time Releases of Mercury to the Atmosphere from Human Activities. Environ Sci Technol 2011; 45:10485-10491. 